\title{
Do Privacy Stress and Brand Trust still Matter? Implications on Continuous Online Purchasing Intention in China
}

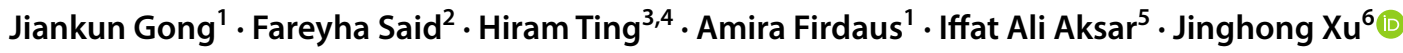

Accepted: 31 January 2022

(c) The Author(s), under exclusive licence to Springer Science+Business Media, LLC, part of Springer Nature 2022

\begin{abstract}
The COVID-19 pandemic has given rise to unprecedented transformations in consumer behaviour. Less is known about how consumers react to privacy stress while being compelled to continuously purchase online during the pandemic. Therefore, underpinned by the stimulus-organism-response (SOR) theory, this paper aims to examine the impacts of perceived Internet risk, self-efficacy, privacy stress, and trust on consumers' continuous purchasing intention in China. Few studies have examined the mediating roles of privacy stress and brand trust in continuous purchasing intention. This research thus adds value by exploring the underlying mechanisms that explain how these factors affect purchasing intention where consumers have little choice but to make purchase online continuously. It employs a quantitative research design and uses a survey questionnaire to collect data. A total of 535 consumers responded and the data were analysed via PLS-SEM. We found mixed results for the direct and indirect paths. Perceived Internet risk, platform trust, and self-efficacy showed significant impacts on privacy stress and brand trust. While brand trust had a significant impact on continuous online purchase intention, contrary to previous literature, privacy stress did not. Moreover, while brand trust was found to be a significant mediator, privacy stress exerted no mediating effect. The results assist marketing practitioners, organizations, and policymakers in improving consumers' online shopping experience in uncertain times by addressing the issues of trust and privacy. Specifically, we provide the foundation for future policies and strategies that build consumers' trust and secure consumers' privacy, especially in highly uncertain contexts.
\end{abstract}

Keywords Privacy stress $\cdot$ COVID-19 $\cdot$ Continuous online purchasing intention $\cdot$ China

\section{Introduction}

At present, the calamitous COVID-19 has not ceased to threaten humankind. Not only is COVID-19 a medical and biological problem, it is a social problem penetrating every field and layer of society (Gong et al., 2021).
As the virus continues to rampage and strict lockdown rules are still in place in many nations, the insurmountable pressure has caused businesses and consumers to undergo a messy, protracted, disordered, multifaceted, and abnormal transformation. For instance, unusual retail consumer behaviours, such as hoarding toilet paper and food, have

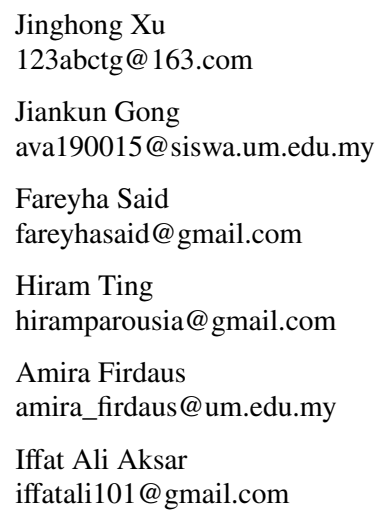

1 Department of Media and Communication Studies, University of Malaya, 50603 Kuala Lumpur, Malaysia

2 Faculty of Business and Accountancy, University of Malaya, 50603 Kuala Lumpur, Malaysia

3 Faculty of Hospitality and Tourism Management, UCSI University, 93050 Kuala Lumpur, Malaysia

4 College of Business, Polytechnic University of the Philippines, 1016 Manila, Philippines

5 Department of Journalism, School of Humanities and Communication, Xiamen University, 43900 Selangor, Malaysia

6 School of Journalism and Communication, Beijing Normal University, Beijing 100875, China 
been reported all over the world (Miri et al., 2020). Indeed, COVID-19 triggered consumers' fear, which led to various coping strategies and adaptation methods as extreme reactions (Kirk and Rifkin, 2020). While many physical stores remain closed, consumers worldwide now rely heavily on online shopping. Interestingly, following the abnormal panic buying period, consumers have settled into a 'temporary normal', which includes infrequently regular trips to certain stores or large amount of online orders to replenish necessities. Responding to these changes in consumer behaviour, businesses have pivoted to online services. Examples include movie streaming via media channels to replace movie theatres, food delivery to replace eating out, and web conferences to replace physical face-to-face meetings. Thus, consumers are now mired in cyberspace, raising major concerns about cybersecurity and privacy.

In fact, amid this temporary period of normalcy, it appears that little attention has been given to the effects of consumers' virtual privacy stress, level of trust on their subsequent purchasing intentions. A deeper examination into this issue indicates that firms and scholars alike appear to have given up on privacy since the pandemic struck. The increased sharing of consumers' private and confidential information online at this time has exacerbated the risk of being leaked or stolen. This phenomenon is what Rosen et al. (2013) call 'the dark side of online consumer behaviour'. Consumers are actually aware of these online risks, as a survey from Statista showed that $64 \%$ of respondents perceived brands' data privacy policies very important while $43 \%$ did not like to perform payment transactions on their phone due to concerns that their data would be stolen (Johnson, 2021). However, privacy paradox exists. On the one hand, consumers are concerned about putting their personal information at risk; on the other, they continue to do what they did before, simply ignoring the potential disadvantage they place themselves at. Under current circumstances, we consider this privacy paradox as a dilemma where consumers must weigh their privacy concerns from high Internet exposure against their need to continuously use it in the rampant epidemic. As such, in the face of dynamic changes and uncertainty, consumers undergo compelled continuity with online purchasing. This study employs the term 'privacy stress' to indicate consumers' worries about data privacy due to unavoidable continuous use and applies it to understand their purchasing intention. Specifically, this study aims to examine: (i) the direct effects of perceived Internet risk, platform trust, and self-efficacy on consumers' privacy stress, brand trust, and continuous purchasing intention; (ii) the direct effects of privacy stress and brand trust on consumers' purchasing intention; and (iii) the indirect effects of perceived Internet risk, platform trust, and self-efficacy on consumers' purchasing intention via the mediation of privacy stress and brand trust.

The effects of antecedent factors like privacy and selfefficacy on purchasing intention have been examined previously. Nevertheless, this study contributes to the current literature in four key ways. First, we incorporate both platform trust and privacy stress into one model. This is important, as the ubiquitous nature of the Internet and the boom in online platforms have given rise to invasions of privacy that may influence consumers' purchasing intention, especially during the pandemic. Second, we add to the relatively small body of literature that explores direct and indirect antecedents of purchasing intention as well as the mediating impacts of brand trust and privacy stress in this context. Third, we examine the novel notion of privacy stress as the unavoidable continuous use of the Internet despite the risk of privacy invasion. Particularly, we use this concept to predict consumers' purchasing intention in an uncertain situation, which adds knowledge on perceptions of privacy in a pandemic. Lastly, our research was conducted in China, a country where privacy is justified as an instrumental good rather than an intrinsic one (Yao-Huai, 2005). Therefore, it is worthwhile to examine these constructs in the Chinese context.

\section{Theoretical Foundations}

The overarching framework is the stimulus-organismresponse (hereafter SOR) model, as extant studies have testified to its predictive power pertaining consumers' reactions to emerging situations (Gao \& Bai, 2014). Additionally, we adopt theoretical constructs from the protectionmotivation theory (Rogers \& Prentice-Dunn, 1997) and the paradox theory (Smith \& Lewis, 2011) to rationalise the causality between relevant variables. Initially, SOR framework of Mehrabian and Russell (1974) focused only on the emotion-eliciting or emotional qualities of an individual's surroundings. Jacoby (2002) presented an integrative SOR model with cognitive and affective systems. The SOR framework conceptualises behaviour or behavioural intention as a product of a certain environment with specific stimuli. The stimuli influence the organism, most often a consumer's emotional, cognitive, or affective process, which eventually give rise to his/her behavioural response. Kim and Lennon (2013) applied the model by positing internal (website quality) and external (reputation) sources of information as stimuli that affect purchase intention (response) through consumers' cognition and emotion (organisms).

The protection-motivation theory (PMT) was employed to support the SOR framework. Originally used to understand the impact of fear appeal, it now posits that people protect themselves based on four factors: perceived severity of a threatening event, perceived probability of occurrence or 
vulnerability, efficacy of recommended preventative behaviour, and perceived self-efficacy (Rogers, 1975). Farooq et al. (2020) utilized the PMT to explain the underlying motives of human actions amid the pandemic. The paradox theory is "a dynamic equilibrium model of organising, which depicts how cyclical responses to paradoxical tensions enable sustainability-peak performance in the present that enables success in the future" (Smith \& Lewis, 2011, p. 381). Previous works on paradox have occurred at the organisational level, neglecting the critical segment of individuals and their social interactions (Waldman et al., 2019). Moreover, a paradox can be treated not only as a tool to predict organisational success but also a problem. By treated as problem, contradictions surface as potentially harmful and likely to entail negative organisational outcomes (Cunha \& Putnam, 2019). This study treats consumers' paradoxical dilemma of online privacy as a problem to understand how privacy stress affects purchasing intention.

Thus, we use the SOR framework to model perceived Internet risk and platform trust as stimuli, consumer selfefficacy, privacy stress, and brand trust as organisms, and purchasing intention as the behavioural response. Additionally, we employ the PMT and paradox theory to unravel the intertwined relationships among these variables.

\section{Research Model and Hypotheses}

\section{Perceived Internet Risk}

Perceived risk serves as an important determinant of consumers' purchasing behaviour. It measures one's uneasiness about using the Internet, which is known for cyber threats that significantly jeopardize online users and businesses. A high level of perceived Internet risk may lead Internet users to exaggerate uncertainties on networking sites, exhibit unwarranted confidence in their judgment. Consumers' perception of online shopping risk has thus become a critical topic of investigation because of its strong effect on customers' attitudes towards online purchases. Accordingly, many studies have examined the direct and indirect effects of perceived Internet risks in the context of consumers' online shopping behaviour. LaRose et al. (2005) discovered that adult consumers' expectations of negative outcomes (risk), such as online scams or online identity theft, were positively related to their privacy loss. Other studies showed that trust is one of the essential in shaping repurchasing intention, while website reputation and perceived risk, which act upon repurchase intention (Lăzăroiu et al., 2020; Martin, 2018; Sullivan \& Kim, 2018). Moreover, Kamalul Ariffin et al. (2018) found that only five types of perceived risks have significant negative influence on consumers' online purchase intention. Likewise, in studying Indian consumers' online banking adoption, Chauhan et al. (2019) revealed that perceived Internet risk has a significant negative influence on consumers' intention to adopt Internet banking. However, with regard to the COVID-19 outbreak, it is unknown whether people still perceive Internet risk in the critical situation. Thus, we postulate the following hypotheses:

H1a: Perceived Internet risk has a positive impact on privacy stress.

H1b: Perceived Internet risk has a negative impact on brand trust.

H1c: Perceived Internet risk has a negative impact on continuous purchasing intention.

\section{Trust in Platform}

"The ultimate goal of marketing is to generate an intense bond between the consumer and the brand, and the main ingredient of this bond is trust" (Hiscock, 2003, p. 1). When risk is present, trust is needed before a buyer is willing to transact with a seller. The concept of trust is multidimensional (Lou \& Yuan, 2019). Although various conceptualisations and definitions of trust have been juxtaposed, there is a general consensus that trust is the expectation that the promise of another can be relied upon and that, in unforeseen circumstances, the other will act in the spirit of goodwill and in a benign fashion towards the trustor (Kim \& Peterson, 2017). From this definition, trust appears to involve a process between the trustor and the trustee. Narrowing our focus to the marketing industry, it can thus be considered the process between the seller and the buyer. Within this process, a consumer must consider whether he/she: (1) trusts the system facilitating the transaction (the Internet); (2) trusts a particular vendor (the seller); (3) trusts other third parties to safeguard the exchange (the platform); and (4) trusts certain brands before a decision is made to purchase online. We categorise trust into platform trust and brand trust.

Luo (2002, p. 115) defined platform trust as "institutions and other third-party guarantors that actually sell/provide certificates pledging integrity, ability, and intent ... [and] in the e-commerce context this type of trust is more likely to solve privacy concerns" and stated that certification provided by third parties "can balance the power and provide the needed trust between the e-vendor and customers." Some scholars have found that institution-based structural assurances (web seals) could positively and substantially affect trustworthiness (Kaplan \& Nieschwietz, 2003). Unsurprisingly, platform trustworthiness is gradually becoming a potent factor affecting consumer purchasing intention. Indeed, consumers can choose various platforms for purchasing, each with different strengths in gratification and visibility features, which may result in varying degrees of consumer trust (Geng et al., 2021). That is, consumers' trust in a platform largely affects their trust in the brand, their 
gratification, and thereby their purchasing intention and commitment to buy again from the same website/platform (Lăzăroiu et al., 2020; Sullivan \& Kim, 2018).

However, when purchasing online, the extent to which consumers trust third-party platforms remains unclear and needs further exploration. For instance, Head and Hassanein (2002) found that the general awareness and influence of web seals is still relatively low, while the impact of thirdparty referees vary according to phases of the trust lifecycle. Due to conflicting views in previous literature, it is vital to examine the relationship between platform trust and consumers' purchasing intention. Considering platform trust as a measure of how well firms comply with applicable information privacy norms, practices, and laws in their day-today business (Kauffman et al., 2011; Wei et al., 2019), we propose that:

H2a: Platform trust has a negative impact on privacy stress.

$\mathrm{H} 2 \mathrm{~b}$ : Platform trust has a positive impact on brand trust.

$\mathrm{H} 2 \mathrm{c}$ : Platform trust has a positive impact on continuous purchasing intention.

\section{Consumer Self-efficacy}

Self-efficacy refers to people's beliefs about their capabilities to produce specific performance levels that influence events affecting their lives. It is a self-evaluation process that mirrors what people believe they can do with their acquired skills (Bandura, 1977). Internet self-efficacy refers to a person's perception of his/her ability to accomplish tasks online (Eastin \& LaRose, 2000). Similarly, Hernandez et al. (2009) stated that e-commerce selfefficacy describes an individual's ability to apply his/her skills to complete a purchase on the Internet. Indeed, prior studies have highlighted the importance of self-efficacy in developing people's present and future e-behaviour (Hill \& Beatty, 2011; Lim et al., 2007). In consumer behaviour field, extant literatures have built causality between self-efficacy, privacy and brand trust. For instance, Akhter (2014)'s study revealed that internet self-efficacy and internet involvement affect privacy concern and stress negatively. Likewise, by investigating the determinants of behavioural responses to online privacy, Hichang (2010) indicated that risk beliefs and self-efficacy have a significant impact on self-protective action. Through two experiments, Keith et al. (2015) demonstrate the strong direct effect of self-efficacy on users' initial trust in locationbased app vendors as well as their perceived risk of disclosing information (privacy). Amid the COVID-19, the quality of the news, and communication in the cyberspace play paramount roles in individuals' decision making and behaviour. With overload information, people increase the perceived Internet risk, which causes response (organism), or coping appraisal. This response contains self-efficacy, response efficacy, and response costs. Prior literature also indicated that environment, trust and self-efficacy could somehow affect individual's behavioural response (Attiq et al., 2017).

Thus, we focus on self-efficacy as consumers' ability to identify their needs and fulfil online purchasing tasks during COVID-19 within the SOR framework. Hence, we hypothesise that:

H3a: Self-efficacy has a negative impact on privacy stress.

H3b: Self-efficacy has a positive impact on brand trust. H3c: Self-efficacy has a positive impact on continuous purchasing intention.

\section{Trust in Brand}

Delgado-Ballester et al. (2003, p. 11) defined brand trust as "the feeling of security held by the consumer in his/her interaction with the brand, that is based on the perceptions that the brand is reliable and responsible for the interests and welfare of the consumer." In other words, brand trust can be regarded as consumers' level of mutual confidence in a brand. Scholars have discovered that brand trust, as a critical precondition of the consumer-brand relationship, can help mitigate volatility, promote positive behaviour, and develop long-term commitment (Jain et al., 2018). Previous research revealed that brand trust mediates the significant effect of brand image on purchasing behaviour (Fianto et al., 2014). It has also been found that brand trust is among several key factors proven to be capable of positively influencing consumer decisions (Amron, 2018). Since the rampant spread of COVID-19, fears and uncertainty concerning the virus have affected consumers' brand trust and purchasing intention. For example, Jian et al. (2020) discovered that customers' fear and uncertainty have raised their environmental awareness, and consequently, their brand trust in green hotels, thereby indicating their willingness to pay more and to stay at green hotels. Therefore, it is worthwhile to explore how brand trust affects consumers' online purchasing intention. Thus, we hypothesise that:

H4a: Brand trust has a positive impact on continuous purchasing intention.

H4b: Brand trust mediates the effect of perceived Internet risk on continuous purchasing intention.

$\mathrm{H} 4 \mathrm{c}$ : Brand trust mediates the effect of platform trust on continuous purchasing intention.

$\mathrm{H} 4 \mathrm{~d}$ : Brand trust mediates the effect of self-efficacy on continuous purchasing intention. 


\section{Privacy Stress}

Privacy issues in marketing and business have been a topic of interest. Although privacy is difficult to conceptualise, in online marketing, it generally has four dimensions: the collection of personal information, the unauthorised secondary use of personal information, errors in personal information, and improper access to personal information (Gerber et al., 2018; Stewart \& Segars, 2002). Concern, according to the Oxford Dictionary, is defined as "be relevant or important to; affect or involve; be a cause of anxiety or worry." Hence, privacy concern is an umbrella term that entails both concern and worry. From the business perspective, it primarily measures the extent to which individuals are concerned about their personal information, especially pertaining to problems like privacy invasion and information leakage or re-trading (Chen et al., 2017; Kehr et al., 2015). Wu et al. (2012) found that the effect of online privacy policies on consumers' willingness to provide personal information on websites is mediated by consumers' privacy concern and level of trust. Similarly, Jibril et al. (2020) established the significant mediating effect of online security and privacy concern on online purchasing intention. Alternatively, we focus on 'privacy stress' in this paper, as stress has a deeper meaning than concern. Privacy concern implies that though a person expresses care about his/her privacy, he/she continues to behave as before, simply ignoring whether the behaviour causes a privacy invasion - hence the term 'privacy paradox'. Contrary to privacy concern, 'privacy stress' means one is so worried or concerned that he/she is driven by this anxiety to either take actions to protect his/her privacy or embrace the stressful yet unavoidable continuous use of online shopping. While experts often cite privacy concern as a barrier to e-commerce, there is a lack of understanding about how privacy stress impacts consumers' continuous purchasing willingness. Thus, we postulate that:

H5a: Privacy stress has a negative impact on continuous purchasing intention.
H5b: Privacy stress mediates the effect of perceived Internet risk on continuous purchasing intention.

H5c: Privacy stress mediates the effect of self-efficacy on continuous purchasing intention.

H5d: Privacy stress mediates the effect of platform trust on continuous purchasing intention.

Figure 1 presents the conceptual framework of this research.

\section{Methods}

\section{Sample and procedures}

To examine how Chinese consumers perceive privacy and its impacts on their purchasing behaviour, online questionnaire was used. The instrument was translated into Chinese, which necessitated several additional steps to be followed. First, the accuracy of the translation was checked through the back-translation method prescribed by Werner and Campbell (1970). Second, the translated instrument was sent for content validity checking to relevant experts in the field.

We purchased the sampling services of WenJuanxing, a technology platform and market research company that arranges samples from the Chinese consumer population based on census data. The benefits of using this official dataset are the reduction of sample homogeneity and the guarantee of quality responses, since WenJuanxing has quality control measures to exclude invalid responses. This study used two filter questions to ensure the suitability of the sampled respondents. The respondents would proceed with the questionnaire only if they provided an affirmative answer to the questions 'Did you have two times or more online shopping experiences in the last month?' and 'Did you have online shopping experiences during the COVID-19?'.

It yielded 535 valid responses in May 2021, which fulfill the statistical and theory generalizability (Lee \& Baskerville, 2003). As such, the study focused on the explanation of

Fig 1. Conceptual Framework

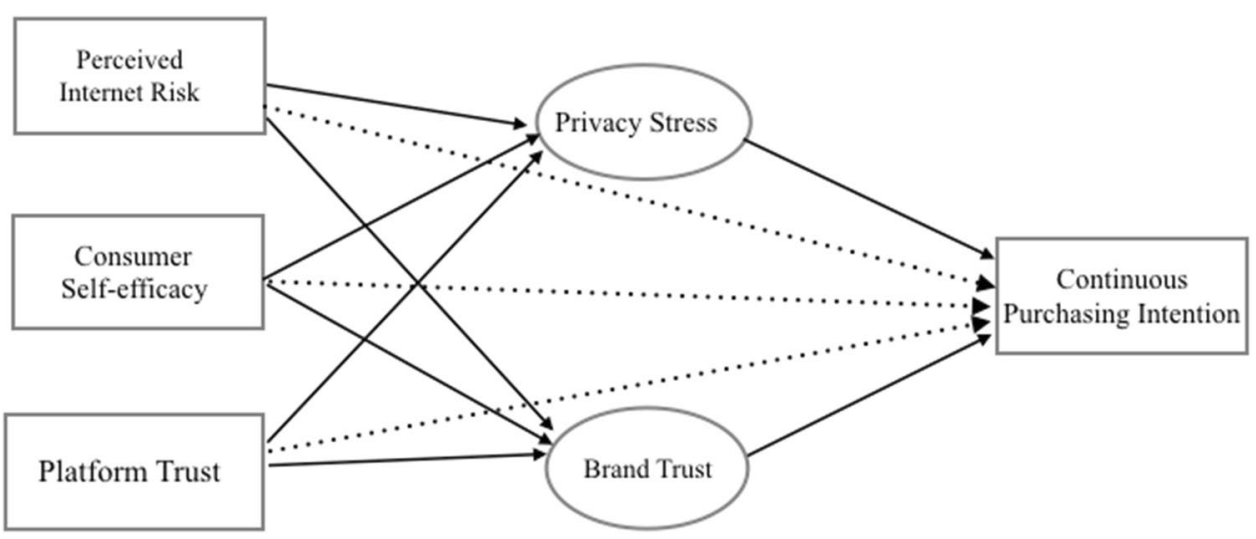


the phenomena from valid responses rather than the generalizability of the study through large number of respondents. Of these respondents, 267 of them $(49.81 \%)$ were male and $269(50.19 \%)$ were female. The average age of the respondents was between 31 and 40 years old. A majority of the participants (73.13 per cent) held a bachelor's degree and earned a monthly income of 776USD to 1550 USD (41.6\%).

It is important to clean and pre-check the data before the main analysis. Pre-checks include the identification of missing values, outliers, and common method variance (CMV). The issue of missing values was avoided through WenJuanxing's quality control procedures. For outlier detection, $\mathrm{z}$-scores were obtained using SPSS. The results showed a minimum and maximum $\mathrm{z}$-score range from -2.91 to -5.29 for all variables. Though a $\mathrm{z}$-score greater than 3.0 indicates an outlier, $\mathrm{Hu}$ and Bentler (1999) recommended that outliers not to be deleted from a data set because it can disturb actual results. Thus, no responses were deleted. Next, CMV occurs when all the variables in a study are examined using the same instrument. Harman's single factor test in SPSS produced a result of $27 \%$ as the maximum variance explained by a single factor, which was lower than the threshold of 50\% (Kock, 2015). Therefore, CMV was not an issue in this study.

\section{Measures}

This paper uses a 7- point Likert scale, and the measurement items are shown in Table 1 . The items for perceived Internet risk were adopted from Grazioli and Jarvenpaa (2000) and Chen (2013). Platform trust was measured using four items adopted from Chen et al. (2019). These items assess consumers' trust towards a particular medium (i.e., Taobao, Facebook) that carries messages about a brand. The selfefficacy of consumers was measured using the items developed by Hernandez et al. (2009) and Koufaris (2002). The measurement of privacy stress was adapted from Malhotra et al. (2004); Smith et al. (1996). The measure for brand trust followed the scale developed by Delgado-Ballester

Table 1: Scale properties

\begin{tabular}{|c|c|c|c|c|c|c|}
\hline Constructs & Labels & Items & Mean & $\lambda$ & $\mathbf{C R}$ & AVE \\
\hline \multirow{3}{*}{$\begin{array}{l}\text { Perceived Internet } \\
\text { Risk }\end{array}$} & InR1 & In general, I feel that it would be risky to engage in Internet activities & 4.66 & 0.88 & \multirow[t]{3}{*}{0.91} & \multirow[t]{3}{*}{0.77} \\
\hline & InR2 & Using Internet will involve many unexpected problems & 4.97 & 0.87 & & \\
\hline & InR3 & I feel unsafe while using Internet & 4.05 & 0.88 & & \\
\hline \multirow{3}{*}{$\begin{array}{l}\text { Consumer } \\
\text { Self-efficacy }\end{array}$} & SeEf1 & I feel capable of using the Internet for purchasing products & 6.39 & 0.78 & \multirow[t]{3}{*}{0.81} & \multirow[t]{3}{*}{0.59} \\
\hline & SeEf2 & I feel capable of locating shopping sites on the Internet & 6.13 & 0.77 & & \\
\hline & SeEf3 & I feel comfortable searching for information about a product on the Internet & 6.01 & 0.74 & & \\
\hline \multirow[t]{4}{*}{ Platform Trust } & PlaT1 & $\begin{array}{l}\text { believe that the shopping platform will protect my personal information in strict } \\
\text { accordance with its "Privacy Statement". }\end{array}$ & 4.82 & 0.89 & \multirow[t]{4}{*}{0.93} & \multirow[t]{4}{*}{0.79} \\
\hline & PlaT2 & $\begin{array}{l}\text { I believe that the shopping platform will consider my interests when collecting, } \\
\text { processing and processing my personal information. }\end{array}$ & 4.66 & 0.87 & & \\
\hline & PlaT3 & $\begin{array}{l}\text { I believe that the shopping platform will use the personal information I provide in } \\
\text { accordance with the promise in the "Privacy Statement". }\end{array}$ & 4.93 & 0.89 & & \\
\hline & PlaT4 & believe that the shopping platform is trustworthy in using my personal information. & 4.73 & 0.89 & & \\
\hline \multirow[t]{4}{*}{ Privacy stress } & PriStre1 & $\begin{array}{l}\text { I am uncomfortable with how my personal information from online purchases is } \\
\text { continually used during the COVID- } 19 \text {. }\end{array}$ & 4.87 & 0.77 & \multirow[t]{4}{*}{0.78} & \multirow[t]{4}{*}{0.57} \\
\hline & PriStre2 & $\begin{array}{l}\text { I am concerned that my friends will see my purchase records on the online shopping } \\
\text { platform if I use continually during the COVID-19. }\end{array}$ & 4.33 & 0.78 & & \\
\hline & PriStre3 & $\begin{array}{l}\text { I am worried that the personal information in the online shopping activities will be } \\
\text { used by other parties without my authorization if I used continuously during the } \\
\text { COVID-19. }\end{array}$ & 4.80 & 0.87 & & \\
\hline & PriStre4 & $\begin{array}{l}\text { To me it is the most important thing to keep my privacy intact from online compa- } \\
\text { nies during the COVID-19. }\end{array}$ & 5.24 & 0.55 & & \\
\hline \multirow[t]{4}{*}{ Brand Trust } & BranT1 & I believe that Brand treats stakeholders like me fairly and justly & 5.04 & 0.84 & \multirow[t]{4}{*}{0.89} & \multirow[t]{4}{*}{0.68} \\
\hline & BranT2 & Brand can be relied on to keep its promises to stakeholders like me & 5.07 & 0.83 & & \\
\hline & BranT3 & I feel very confident about Brand capabilities & 5.05 & 0.81 & & \\
\hline & BranT4 & Brand has the ability to accomplish what it says it will do & 5.24 & 0.81 & & \\
\hline \multirow{3}{*}{$\begin{array}{l}\text { Purchasing } \\
\text { Intention }\end{array}$} & PurcIn1 & I will likely purchase a product over the Internet again during the COVID-19 & 6.00 & 0.84 & \multirow[t]{3}{*}{0.83} & \multirow[t]{3}{*}{0.62} \\
\hline & PurcIn2 & $\begin{array}{l}\text { It is likely that the Internet will continue to be the medium I use to make my pur- } \\
\text { chase during the COVID-19 }\end{array}$ & 5.93 & 0.83 & & \\
\hline & PurcIn3 & I intend to use the Internet to purchase a product regularly during the COVID-19 & 5.50 & 0.68 & & \\
\hline
\end{tabular}


et al. (2003). Purchasing Intention's scale was adapted from Hernandez et al. (2009).

\section{Data analysis}

\section{Measurement model}

The measurement model is evaluated to check convergent validity and internal consistency of the constructs. Generally, all listed indicators and constructs met the reflective measurement criteria. Most outer loadings $(\lambda)$ were above 0.747, excluding two constructs (Hair Jr et al., 2016; Ramayah et al., 2018). Moreover, Composite Reliability (CR) values were 0.789 or higher, clearly above the required minimum level of 0.70 to secure internal consistency. The average variance extracted (AVE) values were all above 0.50 as well, except for one construct that reported a value of 0.425 ; however, the CR value was satisfactory, indicating that overall convergent validity was also achieved for this paper (Hair et al., 2017).

Discriminant validity was assessed by employing the Heterotrait-Monotrait (HTMT) ratio of correlations criterion. As displayed in Table 1, all values were under the threshold value of 0.90 , which was considered satisfactory (Henseler et al., 2015; Ramayah et al., 2018). Additionally, the bootstrapping procedure with 5,000 samples was performed using the no-sign changes option, bootstrap confidence intervals, and two-tailed testing at the 0.05 significance level. The results suggest that none of the HTMT confidence intervals included the values are above 0.90 , indicating that all HTMT values were significantly different from each other (Henseler et al., 2015). Therefore, discriminant validity was established for all the constructs of this study.

\section{Structural Model}

Based on the research hypotheses, the structural model evaluated the effects of perceived Internet risk, self-efficacy, platform trust, brand trust, and privacy stress on continuous purchasing intention using the bootstrapping approach. Privacy stress and brand trust were also tested as mediators between the three independent variables and continuous purchasing intention. The structural model is illustrated in Fig. 2.

Table 2 shows the direct path results. perceived Internet risk was found to significantly increase privacy stress $(\beta=0.523, p=0.00)$ and decrease brand trust $(\beta=-0.097$, $\mathrm{p}<0.001$ ), supporting H1a and H1b. Likewise, platform trust showed a significant negative effect on privacy stress $(\beta=-0.11, p<0.008)$ and a significant positive effect on brand trust $(\beta=0.695, \mathrm{p}=0.00$ ); therefore, $\mathrm{H} 2 \mathrm{a}$ and $\mathrm{H} 2 \mathrm{~b}$ were supported. Unexpectedly, self-efficacy demonstrated a significant yet positive impact on privacy stress $(\beta=0.064$, $\mathrm{p}<0.045$ ) but had a predicted positive impact on brand trust $(\beta=0.117, p=0.00)$. These results supported H3b but rejected H3a. Additionally, we found that privacy stress has a negative but insignificant influence on purchasing intention ( $\beta=-0.02, p<0.66$ ), while brand trust positively and significantly influences purchasing intention $(\beta=0.257, \mathrm{p}=0.00)$. Thus, H4a was confirmed while H5a was rejected.

Finally, perceived Internet risk revealed a positive but insignificant influence on purchasing intention $(\beta=0.007$, $\mathrm{p}=0.855$ ). Likewise, the effect of platform trust on purchasing intention was insignificant $(\beta=-0.099, \mathrm{p}<0.123)$. However, self-efficacy was found to significantly increase purchasing intention $(\beta=0.451, \mathrm{p}<0.000)$. These results indicate that only $\mathrm{H} 3 \mathrm{c}$ was supported as $\mathrm{H} 1 \mathrm{c}$ and $\mathrm{H} 2 \mathrm{c}$ were rejected.

\section{Mediation Analysis}

The bootstrap function was used on Smart PLS to obtain the mediating effect of privacy stress and brand trust between the independent and dependent variables of this study. In order to determine the mediation effect, the direct and indirect effects of privacy stress and brand trust were analysed on continuous purchasing intention following Ramayah et al. (2018). The mediation results in Table 3 shows that only brand trust was found to have a statistically significant mediating effect, while privacy stress had no significant mediating effect.

\section{Coefficient of Determination (R2) and Effect size $\left(\mathrm{f}^{2}\right)$}

In this study, the Smart-PLS algorithm function was used to obtain the coefficient of determination, $\mathrm{R}^{2}$, values. The adjusted $\mathrm{R}^{2}$ for brand trust in this model was 0.565 , which indicated that the endogenous latent variables explained almost $56 \%$ of the variance in brand trust. The adjusted $\mathrm{R}^{2}$ for privacy stress was 0.318 , which means that $31 \%$ of the changes in continuous purchasing intention were explained by endogenous latent variables. The endogenous latent variables explain $27 \%$ of continuous purchasing intention.

Another benchmark of examining the change in the dependent variable is through the assessment of effect size along with reporting of p-value (Durlak, 2009). Hair et al. (2019) have provided the threshold to interpret the effect size values. The values lower than or equal to 0.02 indicates a weak small relationship. The moderate or medium strength of the relationship can be interpreted if the value is greater than 0.15 and lower than 0.35 . The strong effect of the independent variable on dependent variable is predicted if the values are greater than 0.35 . In this study, the effect of brand trust on continuous purchasing intention is 0.04 , which is close to the threshold of small effect. The effect of 


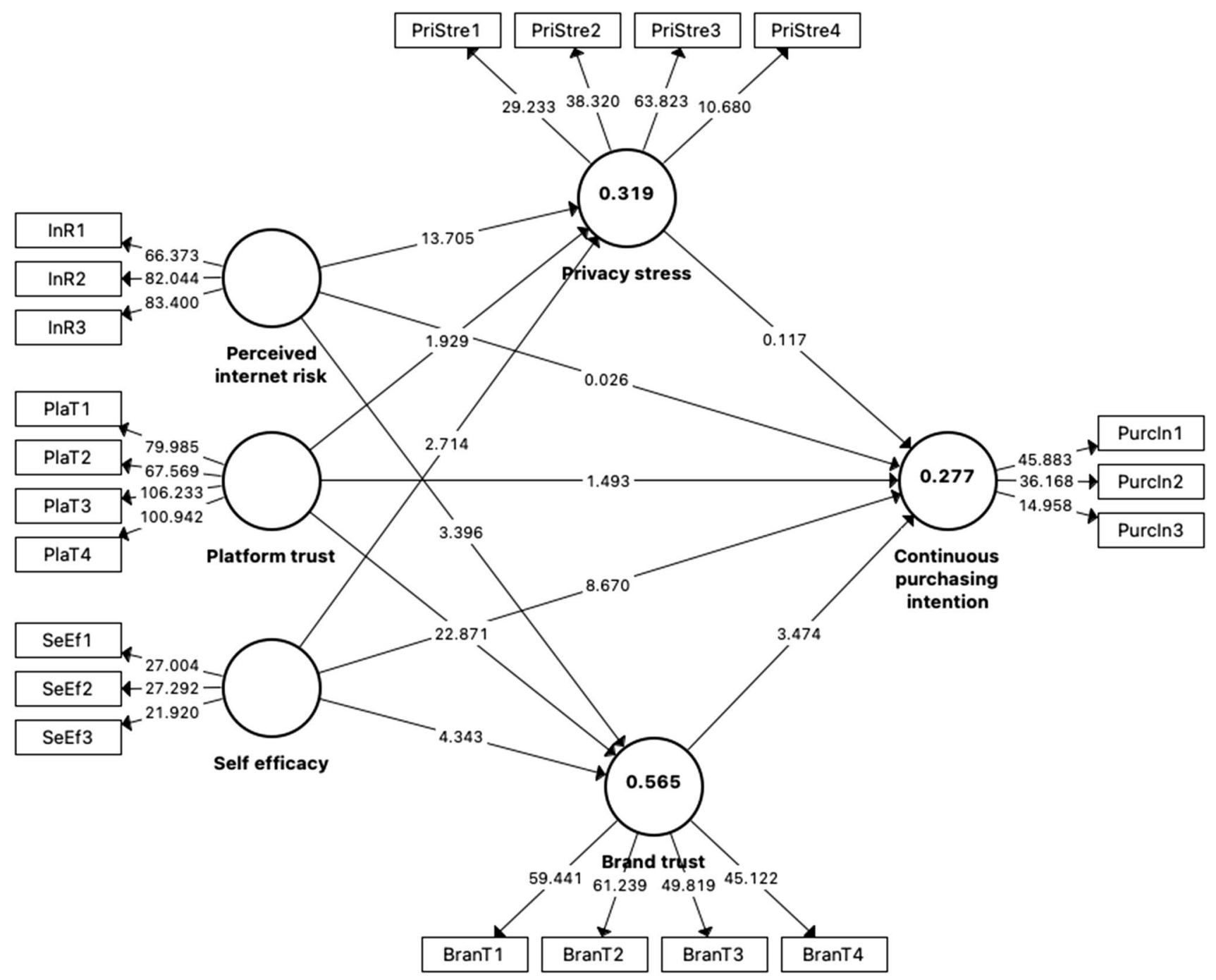

Fig 2. Structural model

Table 2 Heterotrait-Monotrait (HTMT) Results

\begin{tabular}{lllllll}
\hline & & $\mathbf{1}$ & $\mathbf{3}$ & $\mathbf{4}$ & $\mathbf{6}$ \\
\hline 1 & Brand trust & & & & \\
2 & Perceived & 0.37 & & & \\
& Internet risk & $\mathrm{CI}_{0.95}(0.28 ; 0.45)$ & & & \\
3 & Platform trust & 0.83 & 0.34 & & & \\
& & $\mathrm{CI}_{0.95}(0.78 ; 0.88)$ & $\mathrm{CI}_{0.95}(0.25 ; 0.43)$ & & & \\
4 & Privacy Stress & 0.22 & 0.65 & 0.25 & \\
& & $\mathrm{CI}_{0.95}(0.15 ; 0.32)$ & $\mathrm{CI}_{0.95}(0.56 ; 0.74)$ & $\mathrm{CI}_{0.95}(0.18 ; 0.35)$ & & \\
5 & Continuous Pur- & 0.37 & 0.18 & 0.19 & 0.13 \\
& chasing Intention & $\mathrm{CI}_{0.95}(0.25 ; 0.49)$ & $\mathrm{CI}_{0.95}(0.12 ; 0.27)$ & $\mathrm{CI}_{0.95}(0.13 ; 0.29)$ & $\mathrm{CI}_{0.95}(0.09 ; 0.21)$ & 0.15 \\
6 & Self-efficacy & 0.25 & 0.19 & 0.15 & $\mathrm{CI}_{0.95}(0.12 ; 0.23)$ & $\mathrm{CI}_{0.95}(0.55 ; 0.86)$ \\
& & $\mathrm{CI}_{0.95}(0.16 ; 0.35)$ & $\mathrm{CI}_{0.95}(0.15 ; 0.28)$ & $\mathrm{CI}_{0.95}(0.11 ; 0.24)$ & $\mathrm{CI}_{0.95}$ \\
\hline
\end{tabular}

Note: $\mathrm{CI}=$ Confidence interval 
Table 3 Specific indirect effects

\begin{tabular}{|c|c|c|c|c|c|c|c|}
\hline \multirow[t]{2}{*}{ Path } & \multirow[t]{2}{*}{ Beta } & \multirow[t]{2}{*}{ SE } & \multirow[t]{2}{*}{ t-value } & \multirow[t]{2}{*}{ p-value } & \multicolumn{2}{|c|}{$\begin{array}{l}\text { Confidence } \\
\text { interval (CI) }\end{array}$} & \multirow[t]{2}{*}{ Decision } \\
\hline & & & & & LL & UL & \\
\hline $\begin{array}{l}\text { Perceived Internet risk } \rightarrow \text { Brand trust } \rightarrow \text { Continuous Purchasing Inten- } \\
\text { tion }\end{array}$ & -0.025 & 0.01 & 2.399 & 0.016 & -0.051 & -0.01 & Mediation \\
\hline Self-efficacy $\rightarrow$ Brand trust $\rightarrow$ Continuous Purchasing Intention & 0.03 & 0.011 & 2.663 & 0.008 & 0.013 & 0.056 & \\
\hline Platform trust $\rightarrow$ Brand trust $\rightarrow$ Continuous Purchasing Intention & 0.179 & 0.05 & 3.536 & 0.00 & 0.086 & 0.278 & \\
\hline $\begin{array}{l}\text { Perceived Internet risk } \rightarrow \text { Privacy stress } \rightarrow \text { Continuous Purchasing } \\
\text { Intention }\end{array}$ & -0.011 & 0.025 & 0.434 & 0.665 & -0.058 & 0.04 & No mediation \\
\hline Self-efficacy $\rightarrow$ Privacy stress $\rightarrow$ Continuous Purchasing Intention & -0.001 & 0.003 & 0.391 & 0.695 & -0.011 & 0.004 & \\
\hline Platform trust $\rightarrow$ Privacy stress $\rightarrow$ Continuous Purchasing Intention & 0.002 & 0.006 & 0.407 & 0.684 & -0.008 & 0.016 & \\
\hline
\end{tabular}

self-efficacy on brand trust value is 0.006 , this shows a small effect whereas the effect size value of 0.268 for privacy stress shows a moderate effect of self-efficacy. The effect of internet risk on brand trust is 0.019 , and on continuous purchasing intention is 0.00 , which also shows a weak or minimal effect. A strong or substantial impact of internet risk on privacy stress can be observed of 0.361 . Likewise, a large or strong effect size of platform trust on brand trust can be seen from the value of 1.00 .

\section{Discussion and Implications}

Theoretically, this study has found that only consumers' self-efficacy directly influences their purchasing intention, as opposed to their perceptions of perceived Internet risk and platform trust. Moreover, we concurrently tested the mediating effects of privacy stress and brand trust. Although all these relationships have been proven separately in the extant literature (Compeau \& Higgins, 1995; Featherman \& Pavlou, 2003; Hernandez et al., 2009; McCole et al., 2010; Wu et al., 2012), to the best of our knowledge, there is limited or even no research that has tested these variables in the same model. Furthermore, this study examined them in the context of crisis and uncertainty, wherein consumer attitudes, perceptions, and behaviours are changeable, unpredictable, and even abnormal (Laato et al., 2020; Liu et al., 2020). The findings also add new knowledge by introducing the notion of privacy stress to understand consumer's unavoidable yet continuous use of online shopping in this uncertain condition. Hence, against the current backdrop, this study gives refreshing insights into consumers' continuous purchasing intention. Additionally, this study employed the SOR framework, coupled with supporting theories like the PMT and paradox theory, to investigate consumers' purchasing intention in the context of a pandemic. It is important to synthesise various theoretical reasonings to explain emerging phenomena; in this regard, our study serves as a pioneer.
Interestingly, we found that privacy stress does not mediate the impacts of perceived Internet risk, self-efficacy, and platform trust on consumers' purchasing intention amid the worldwide pandemic, which conflicts with the works of Jibril et al. (2020) and Wu et al. (2012). The potential reasons are threefold. First, privacy is not only notoriously hard to define but is also a multidimensional umbrella term that is difficult to accurately examine (Gerber et al., 2018; Preibusch, 2013). Even though we proposed the concept of privacy stress as distinct from privacy concern or privacy valuation, the nuances among the terms are still hard for the general population to distinguish. Moreover, the privacy paradox is in motion, meaning that consumers are ostensibly concerned about their privacy when making online purchases, but are also known to provide personal information in exchange for small discounts or rewards (Tsai et al., 2011).

Second, when the pandemic is rampant, people exchange their privacy for security. As Jennifer King, Director of Privacy at the Centre for Internet and Society at Stanford Law School, put it: "There have been some different incursions into people's lives." People are locked down at home, so online shopping is the only way for most, if not all, to shop. Furthermore, they are not only encouraged to gather more data and expose themselves to more information in their daily lives, but are also convinced that this tracking may have public health benefits. To conclude, the pandemic and its ensuing uncertainty have transformed people to a new norm of online shopping, and it seems that the previous findings of privacy concern/worry/ stress does not fit into the epidemic situation. This finding adds new sight into understanding privacy issue in different conditions.

Third, the socio-cultural background is a potent factor in examining privacy. This study was conducted in China, a densely populated country with a culture of collectivism that prescribes privacy as more of an instrumental good than a practical action (Yao-Huai, 2020). Kui (2021) gives a more updated idea, arguing that China is confronted with fulfilling the task of public health surveillance while simultaneously 
protecting personal privacy. However, three factors have caused these balancing efforts to falter: a) the lack of a strong surveillance mechanism; b) huge social mobilisation; and c) collectivist thinking and obedience. These findings happened to coincide with ours and are in line with the assertion that when we treat paradox as a problem, it has potentially harmful and negative outcomes (Cunha \& Putnam, 2019). That is to say, consumers gave up their privacy when they contradicted themselves via continuous buying and limited privacy-protection. Overall, this implies that the privacy issue is still in its early stages in China. Thus, it is no surprise that privacy stress failed to exert a mediating effect in our study.

Regarding practical implications, since the mediation of trust is significant, it indicates a need to build and maintain trust in the online environment (McCole et al., 2010). This trust encompasses platform and third-party trust (Luo, 2002), as well as brand trust. Since fears and risk related to the Internet remain an obstacle between businesses and their consumers, trust on behalf of both sides still serves as the precursor to online buying and recurrent purchasing behaviour (de Morais Watanabe et al., 2020; Gefen \& Straub, 2004). Therefore, when it comes to the dual relationships between consumer and venders, trust in the vendor is important for the consumer to accept potential risk. This indicates that online vendors should put continued efforts to instill trust instead of taking it for granted. Also, high trustworthiness underpins individual wellbeing (Nataliya, 2015), which suggests that the enhancement of trust could catalyse consumers' and even societies' wellbeing, which might remind policy-makers to take corresponding measures. Lastly, privacy stress is not significant, which reflects that people tend to concede privacy protection during uncertainty. From a macro level, government bodies and decision makers should balance public health protection as well as privacy protection. It calls for a sounder response mechanism and polices amid high-risk periods.

\section{Limitations and Future Directions}

The present study has some limitations that may provide further direction for future research. Firstly, the study was conducted in China, due to the diversity of demographics in China, different personality and social background might have an impact of consumer behaviour. As such the findings of the study cannot be construed to the entire population in China. Although the present study focuses on explanation rather than sampling generalizability, future studies with more substantial sample size can be done to make comparisons and provide more insights in different contexts. Secondly, the study only looked into privacy stress There are other forms of stress which might potentially affect their mental well-being and subsequent behaviour. Hence, it provides opportunities for further investigations to explore other potential determinants. Thirdly, the study was done when COVID-19 still poses a threat to health and social wellbeing. Even though government has made efforts to alleviate its negative impact and resume business activities into a new norm, it might not fully explain repeated behaviour during and after pandemic. Considering the uncertainty of the contemporary environment, future research should look into germane issues in order to gain better insights of continuous purchase intention and other behavioural factors (Cheer et al., 2021; Ting et al., 2020).

Acknowledgements This article has been produced as part of the major project of the National Social Science Fund of China, Research on the Establishment of Omnimedia Communication System (Grant No. 20ZDA057).

\section{Declarations}

Conflict of Interest On behalf of all authors, the corresponding author states that there is no conflict of interest.

Ethical Approval All procedures performed in studies involving human participants were in accordance with the ethical standards of the institutional research committee (Beijing Normal University) and with the 1964 Helsinki declaration and its later amendments or comparable ethical standards.

Informed Consent Informed consent was obtained from all individual participants included in the study.

\section{References}

Akhter, S. H. (2014). Privacy concern and online transactions: the impact of internet self-efficacy and internet involvement. Journal of Consumer Marketing.

Amron, A. (2018). The influence of brand image, brand trust, product quality, and price on the consumer's buying decision of MPV cars. European Scientific Journal, 14(13), 228-239.

Attiq, S., Rasool, H., \& Iqbal, S. (2017). The impact of supportive work environment, trust, and self-efficacy on organizational learning and its effectiveness: A stimulus-organism response approach. Business \& Economic Review, 9(2), 73-100.

Bandura, A. (1977). Self-efficacy: toward a unifying theory of behavioral change. Psychological review, 84(2), 191.

Chauhan, V., Yadav, R., \& Choudhary, V. (2019). Analyzing the impact of consumer innovativeness and perceived risk in internet banking adoption. International Journal of Bank Marketing.

Cheer, J., Ting, H., \& Leong, C. (2021). Responsible tourism: a new era of responsibility? Journal of Responsible Tourism Management, 1(1), 1-17.

Chen, H., Beaudoin, C. E., \& Hong, T. (2017). Securing online privacy: An empirical test on Internet scam victimization, online privacy concerns, and privacy protection behaviors. Computers in human behavior, 70, 291-302.

Chen, R. (2013). Living a private life in public social networks: An exploration of member self-disclosure. Decision support systems, 55(3), 661-668. 
Compeau, D. R., \& Higgins, C. A. (1995). Computer self-efficacy: Development of a measure and initial test. MIS quarterly, 189-211.

Cunha, M. P. E., \& Putnam, L. L. (2019). Paradox theory and the paradox of success. Strategic organization, 17(1), 95-106.

de Morais Watanabe, E. A., Alfinito, S., Curvelo, I. C. G., \& Hamza, K. M. (2020). Perceived value, trust and purchase intention of organic food: a study with Brazilian consumers. British Food Journal.

Delgado-Ballester, E., Munuera-Aleman, J. L., \& Yague-Guillen, M. J. (2003). Development and validation of a brand trust scale. International journal of market research, 45(1), 35-54.

Durlak, J. A. (2009). How to select, calculate, and interpret effect sizes. Journal of pediatric psychology, 34(9), 917-928.

Eastin, M. S., \& LaRose, R. (2000). Internet self-efficacy and the psychology of the digital divide. Journal of computer-mediated communication, 6(1), JCMC611.

Farooq, A., Laato, S., \& Islam, A. N. (2020). Impact of online information on self-isolation intention during the COVID-19 pandemic: cross-sectional study. Journal of medical Internet research, 22(5), e19128.

Featherman, M. S., \& Pavlou, P. A. (2003). Predicting e-services adoption: a perceived risk facets perspective. International journal of human-computer studies, 59(4), 451-474.

Fianto, A. Y. A., Hadiwidjojo, D., \& Aisjah, S. (2014). The influence of brand image on purchase behaviour through brand trust. Business Management and Strategy, 5(2), 58.

Gao, L., \& Bai, X. (2014). Online consumer behaviour and its relationship to website atmospheric induced flow: Insights into online travel agencies in China. Journal of Retailing and Consumer Services, 21(4), 653-665.

Gefen, D., \& Straub, D. W. (2004). Consumer trust in B2C e-Commerce and the importance of social presence: experiments in e-Products and e-Services. Omega, 32(6), 407-424.

Geng, S., Yang, P., Gao, Y., \& Tan, Y. (2021). The effects of ad social and personal relevance on consumer ad engagement on social media: the moderating role of platform trust. Computers in human behavior, 106834.

Gerber, N., Gerber, P., \& Volkamer, M. (2018). Explaining the privacy paradox: A systematic review of literature investigating privacy attitude and behavior. Computers \& security, 77, 226-261.

Gong, J., Zanuddin, H., Hou, W., \& Xu, J. (2021). Media attention, dependency, self-efficacy, and prosocial behaviours during the outbreak of COVID-19: A constructive journalism perspective. Global Media and China, O(0), 20594364211021331. https://doi. org/10.1177/20594364211021331

Grazioli, S., \& Jarvenpaa, S. L. (2000). Perils of Internet fraud: An empirical investigation of deception and trust with experienced Internet consumers. IEEE Transactions on Systems, Man, and Cybernetics-Part A: Systems and Humans, 30(4), 395-410.

Hair, J. F., Hult, G. T. M., Ringle, C. M., Sarstedt, M., \& Thiele, K. O. (2017). Mirror, mirror on the wall: a comparative evaluation of composite-based structural equation modeling methods. Journal of the Academy of Marketing Science, 45(5), 616-632.

Hair, J. F., Risher, J. J., Sarstedt, M., \& Ringle, C. M. (2019). When to use and how to report the results of PLS-SEM. European Business Review.

Hair Jr, J. F., Hult, G. T. M., Ringle, C., \& Sarstedt, M. (2016). A primer on partial least squares structural equation modeling (PLS-SEM). Sage publications.

Head, M. M., \& Hassanein, K. (2002). Trust in e-commerce: Evaluating the impact of third-party seals. Quarterly journal of electronic commerce, 3, 307-326.

Henseler, J., Ringle, C. M., \& Sarstedt, M. (2015). A new criterion for assessing discriminant validity in variance-based structural equation modeling. Journal of the Academy of Marketing Science, 43(1), 115-135. https://doi.org/10.1007/s11747-014-0403-8

Hernandez, B., Jimenez, J., \& Jose Martin, M. (2009). The impact of self-efficacy, ease of use and usefulness on e-purchasing: An analysis of experienced e-shoppers. Interacting with computers, 21(1-2), 146-156.

Hichang, C. (2010). Determinants of Behavioral Responses to Online Privacy: The Effects of Concern, Risk Beliefs, Self-Efficacy, and Communication Sources on Self-Protection Strategies. Journal of Information Privacy and Security, 6(1), 3-27. https://doi.org/10. 1080/15536548.2010.10855879

Hill, W. W., \& Beatty, S. E. (2011). A model of adolescents' online consumer self-efficacy (OCSE). Journal of Business Research, 64(10), 1025-1033.

Hiscock, J. (2003). Most trusted brands 2002. Marketing, 1 .

Hu, L. T., \& Bentler, P. M. (1999). Cutoff criteria for fit indexes in covariance structure analysis: Conventional criteria versus new alternatives. Structural equation modeling: a multidisciplinary journal, 6(1), 1-55.

Jacoby, J. (2002). Stimulus-organism-response reconsidered: an evolutionary step in modeling (consumer) behavior. Journal of Consumer Psychology, 12(1), 51-57.

Jain, N. K., Kamboj, S., Kumar, V., \& Rahman, Z. (2018). Examining consumer-brand relationships on social media platforms. Marketing Intelligence \& Planning.

Jian, Y., Yu, I. Y., Yang, M. X., \& Zeng, K. J. (2020). The Impacts of Fear and Uncertainty of COVID-19 on Environmental Concerns, Brand Trust, and Behavioral Intentions toward Green Hotels. Sustainability, 12(20), 8688

Jibril, A. B., Kwarteng, M. A., Nwaiwu, F., Appiah-Nimo, C., Pilik, M., \& Chovancova, M. (2020). Online identity theft on consumer purchase intention: A mediating role of online security and privacy concern. Conference on E-Business, e-Services and e-Society,

Johnson, J. (2021). U.S. online consumer concerns about brands and data privacy $2019 \mathrm{https}: / / \mathrm{www}$.statista.com/statistics/308707/ company-transparency-regarding-consumer-data-usage/

Kamalul Ariffin, S., Mohan, T., \& Goh, Y.-N. (2018). Influence of consumers' perceived risk on consumers' online purchase intention. Journal of Research in Interactive Marketing, 12(3), 309-327. https://doi.org/10.1108/JRIM-11-2017-0100

Kaplan, S. E., \& Nieschwietz, R. J. (2003). A Web assurance services model of trust for B2C e-commerce. International Journal of Accounting Information Systems, 4(2), 95-114.

Kauffman, R. J., Lee, Y. J., Prosch, M., \& Steinbart, P. J. (2011). A survey of consumer information privacy from the accounting information systems perspective. Journal of Information Systems, 25(2), 47-79.

Kehr, F., Kowatsch, T., Wentzel, D., \& Fleisch, E. (2015). Blissfully ignorant: the effects of general privacy concerns, general institutional trust, and affect in the privacy calculus. Information Systems Journal, 25(6), 607-635.

Keith, M. J., Babb, J. S., Lowry, P. B., Furner, C. P., \& Abdullat, A. (2015). The role of mobile-computing self-efficacy in consumer information disclosure. Information Systems Journal, 25(6), 637667. https://doi.org/10.1111/isj.12082

Kim, J., \& Lennon, S. J. (2013). Effects of reputation and website quality on online consumers' emotion, perceived risk and purchase intention. Journal of Research in Interactive Marketing.

Kim, Y., \& Peterson, R. A. (2017). A Meta-analysis of Online Trust Relationships in E-commerce. Journal of Interactive Marketing, $38,44-54$

Kirk, C. P., \& Rifkin, L. S. (2020). I'll trade you diamonds for toilet paper: Consumer reacting, coping and adapting behaviors in the COVID-19 pandemic. Journal of Business Research, 117, $124-131$. 
Kock, N. (2015). Common method bias in PLS-SEM: A full collinearity assessment approach. International Journal of e-Collaboration (ijec), 11(4), 1-10.

Koufaris, M. (2002). Applying the technology acceptance model and flow theory to online consumer behavior. Information systems research, 13(2), 205-223.

Kui, S. (2021). The Stumbling Balance between Public Health and Privacy amid the Pandemic in China. The Chinese Journal of Comparative Law.

Laato, S., Islam, A. N., Farooq, A., \& Dhir, A. (2020). Unusual purchasing behavior during the early stages of the COVID-19 pandemic: The stimulus-organism-response approach. Journal of Retailing and Consumer Services, 57, 102224.

LaRose, R., Rifon, N., Liu, S., \& Lee, D. (2005). Understanding online safety behavior: A multivariate model. The 55th annual conference of the international communication association, New York city,

Lăzăroiu, G., Neguriţă, O., Grecu, I., Grecu, G., \& Mitran, P. C. (2020). Consumers' Decision-Making Process on Social Commerce Platforms: Online Trust, Perceived Risk, and Purchase Intentions [Mini Review]. Frontiers in Psychology, 11. https:// doi.org/10.3389/fpsyg. 2020.00890

Lee, A. S., \& Baskerville, R. L. (2003). Generalizing Generalizability in Information Systems Research. Information systems research, 14(3), 221-243. https://doi.org/10.1287/isre.14.3.221. 16560

Lim, H., Lee, S.-G., \& Nam, K. (2007). Validating E-learning factors affecting training effectiveness. International Journal of Information Management, 27(1), 22-35.

Liu, X., Luo, W.-T., Li, Y., Li, C.-N., Hong, Z.-S., Chen, H.-L., et al. (2020). Psychological status and behavior changes of the public during the COVID-19 epidemic in China. Infectious diseases of poverty, 9, 1-11.

Lou, C., \& Yuan, S. (2019). Influencer marketing: how message value and credibility affect consumer trust of branded content on social media. Journal of Interactive Advertising, 19(1), 58-73.

Luo, X. (2002). Trust production and privacy concerns on the Internet: A framework based on relationship marketing and social exchange theory. Industrial Marketing Management, 31(2), 111-118.

Malhotra, N. K., Kim, S. S., \& Agarwal, J. (2004). Internet users' information privacy concerns (IUIPC): The construct, the scale, and a causal model. Information systems research, 15(4), 336-355.

Martin, K. (2018). The penalty for privacy violations: How privacy violations impact trust online. Journal of Business Research, 82, 103-116.

McCole, P., Ramsey, E., \& Williams, J. (2010). Trust considerations on attitudes towards online purchasing: The moderating effect of privacy and security concerns. Journal of Business Research, 63(9-10), 1018-1024.

Mehrabian, A., \& Russell, J. A. (1974). An approach to environmental psychology. the MIT Press.

Miri, S. M., Roozbeh, F., Omranirad, A., \& Alavian, S. M. (2020). Panic of buying toilet papers: a historical memory or a horrible truth? Systematic review of gastrointestinal manifestations of COVID-19. Hepat. Mon, 20(3).

Nataliya, P. (2015). Trust as wellbeing factor. Procedia-Social and Behavioral Sciences, 166, 147-151.

Preibusch, S. (2013). Guide to measuring privacy concern: Review of survey and observational instruments. International journal of human-computer studies, 71(12), 1133-1143.

Ramayah, T., Cheah, J., Chuah, F., Ting, H., \& Memon, M. A. (2018). Partial least squares structural equation modeling (PLS-SEM) using smartPLS 3.0. In: Kuala Lumpur: Pearson.

Rogers, R. W. (1975). A Protection Motivation Theory of Fear Appeals and Attitude Change1. The Journal of Psychology, 91(1), 93-114. https://doi.org/10.1080/00223980.1975.9915803
Rogers, R. W., \& Prentice-Dunn, S. (1997). Protection motivation theory.

Rosen, L. D., Whaling, K., Rab, S., Carrier, L. M., \& Cheever, N. A. (2013). Is Facebook creating "iDisorders"? The link between clinical symptoms of psychiatric disorders and technology use, attitudes and anxiety. Computers in human behavior, 29(3), 1243-1254.

Smith, H. J., Milberg, S. J., \& Burke, S. J. (1996). Information privacy: Measuring individuals' concerns about organizational practices. MIS quarterly, 167-196.

Smith, W. K., \& Lewis, M. W. (2011). Toward a theory of paradox: A dynamic equilibrium model of organizing. Academy of management Review, 36(2), 381-403.

Stewart, K. A., \& Segars, A. H. (2002). An empirical examination of the concern for information privacy instrument. Information systems research, 13(1), 36-49.

Sullivan, Y. W., \& Kim, D. J. (2018). Assessing the effects of consumers' product evaluations and trust on repurchase intention in e-commerce environments. International Journal of Information Management, 39, 199-219.

Ting, H., Jean, L. X., Meng, L. C., Cheah, J.-H., \& Cheer, J. M. (2020). Editorial-responsible tourism: A call to action for turbulent times. Asian Journal of Business Research Volume, 10(2).

Tsai, J. Y., Egelman, S., Cranor, L., \& Acquisti, A. (2011). The effect of online privacy information on purchasing behavior: An experimental study. Information systems research, 22(2), 254-268.

Waldman, D. A., Putnam, L. L., Miron-Spektor, E., \& Siegel, D. (2019). The role of paradox theory in decision making and management research. Organizational Behavior and Human Decision Processes, 155, 1-6.

Wei, K., Li, Y., Zha, Y., \& Ma, J. (2019). Trust, risk and transaction intention in consumer-to-consumer e-marketplaces: An empirical comparison between buyers' and sellers' perspectives. Industrial Management \& Data Systems.

Werner, O., \& Campbell, D. T. (1970). Translating, working through interpreters, and the problem of decentering. A handbook of method in cultural anthropology, 398, 420.

Wu, K.-W., Huang, S. Y., Yen, D. C., \& Popova, I. (2012). The effect of online privacy policy on consumer privacy concern and trust. Computers in human behavior, 28(3), 889-897.

Yao-Huai, L. (2005). Privacy and data privacy issues in contemporary China. Ethics and Information Technology, 7(1), 7-15.

Yao-Huai, L. (2020). Privacy and data privacy issues in contemporary China. In The Ethics of Information Technologies (pp. 189-197). Routledge.

Publisher's Note Springer Nature remains neutral with regard to jurisdictional claims in published maps and institutional affiliations.

Jiankun Gong PhD candidate, at Department of Media and Communication Studies, Faculty of Arts and Social Sciences, University of Malaya, Malaysia.

Fareyha Said, PhD candidate, Faculty of Business and Accountancy, University of Malaya. Her research interests focus on consumer behavior, sustainable accounting.

Hiram Ting Associate Professor at Faculty of Hospitality and Tourism Management, UCSI University and College of Business, Polytechnic University of the Philippines, Philippines. He has served as a guest editor for a few journals, including British Food Journal, Journal of Hospitality and Tourism Research, Young Consumers, International Journal of Ecommerce Studies and Sustainability. 
Amira Firdaus Deputy Director / Acting Head for Leadership \& Wellbeing (LeadWell) Academic Enhancement \& Leadership Development Centre (ADeC) \& Associate Professor, Department of Media and Communication Studies, Faculty of Arts and Social Sciences, University of Malaya, Malaysia

Iffat Ali Aksar, an assistant professor at the School of Humanities and Communication, Xiamen University, Malaysia. Her research interests include women's study, wellbeing, marginalized group and social media.
Jinghong Xu, Professor at the School of Journalism and Communication, Beijing Normal University. His research interests include new media and internet governance, health communication, inter-cultural communication, film and television study, and game research. 